\title{
Poloxamer and Chitosan-Based In Situ Gels Loaded with Orthosiphon stamineus Benth. Extracts Containing Rosmarinic Acid for the Treatment of Ocular Infections
}

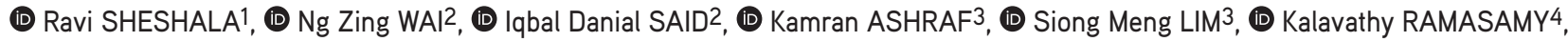 \\ (1D Farrukh ZEESHAN2* \\ 1 Universiti Teknologi MARA, Faculty of Pharmacy, Department of Pharmaceutics, Selangor, Malaysia \\ 2International Medical University, School of Pharmacy, Department of Pharmaceutical Technology, Kuala Lumpur, Malaysia \\ 3Universiti Teknologi MARA, Faculty of Pharmacy, Department of Pharmacology and Pharmaceutical Chemistry, Selangor, Malaysia \\ 4Universiti Teknologi MARA, Faculty of Pharmacy, Department of Pharmaceutical Life Sciences, Selangor, Malaysia
}

\begin{abstract}
Objectives: Orthosiphon stamineus Benth. (OS) is a commonly used medicinal plant for curbing bacterial infections globally. This work aimed to fabricate poloxamer and chitosan-based in situ gels loaded with standardized aqueous-ethanolic OS leaf extracts and investigate their antimicrobial efficacy as a potential remedy against ocular infections.

Materials and Methods: In situ gels containing $0.5 \% \mathrm{w} / \mathrm{v}$ OS extract prepared using cold dispersion method were subjected to physicochemical characterization, including in vitro-release studies. Antimicrobial efficacy was tested against Staphylococcus aureus, Micrococcus luteus, Escherichia coli, and Pseudomonas aeruginosa using agar diffusion method.

Results: Thin layer chromatography and high performance liquid chromatography chromatograms confirmed the presence of rosmarinic acid (RA) and sinensitin in OS extracts with same retention factor (0.26 and 0.49) and retention times (12.2 and 20.7 min) against reference standards. A homogenous brown coloured in situ gel exhibited low viscosity as a solution and increased viscosity in gel form at ocular temperature. The optimized formulations, P7 (21\% P407/4\% P188), P8 (21\% P407/5\% P188) and F5 (1.5\% chitosan and $45 \%$-glycerophosphate) exhibited ideal ocular $\mathrm{pH}(7.27-7.46)$, phase transition at ocular temperature $\left(33-37^{\circ} \mathrm{C}\right)$ and prolonged RA release up to $12 \mathrm{~h}$. Formulation F5 showed an inhibition zone of $4.3 \mathrm{~mm}$ against M. luteus.

Conclusion: Among all, formulation F5 alone exhibited modest antimicrobial activity against M. luteus. OS extracts at $5 \%$ and $10 \%$ were most active against tested bacteria however, loading them into in situ gels resulted in sedimentation. Hence, isolation of RA from OS extract is suggested before loading into formulations for a better antimicrobial activity.
\end{abstract}

Key words: Chitosan, in situ gels, ocular infections, Orthosiphon stamineus, poloxamer

\section{INTRODUCTION}

Ocular infections such as conjunctivitis, keratitis, endophthalmitis, blepharitis, and orbital cellulitis if left untreated, damage the structures of the eye, which may possibly lead to visual impairments and blindness. ${ }^{1,2}$ Conventional ocular dosage forms such as eye drop therapy require frequent administration, have limited duration of action and encounter rapid drainage from the eyes leading to poor ocular drug bioavailability $\left(\langle 5 \%){ }^{3}\right.$ To overcome these limitations, in situ gels can be a potential alternative to eye drops as they exist as free- 
flowing liquids before instillation into the eyes and transform into semi-solid gels upon exposure to ocular conditions such as $\mathrm{pH}$, temperature or ionic concentration. ${ }^{4}$ Although numerous in situ gelling systems have been developed, thermosensitive in situ gels are attracting popularity because of their swift response to a change in the temperature of surrounding environment. Thermosensitive in situ gels exist as a solutions at room temperature $\left(25^{\circ} \mathrm{C}\right)$ but transform at ocular temperature (33- $\left.37^{\circ} \mathrm{C}\right)$ into gel. ${ }^{5,6}$

Several polymers have been employed in the development of in situ gelling systems intended for ocular delivery. However, being biocompatible, biodegradable, non-toxic, and bioadhesive, chitosan is an ideal polymer. ${ }^{3,7}$ Nevertheless, because of $\mathrm{pH}$-dependent the activity of chitosan, it would not render a thermosensitive in situ gel. ${ }^{8}$ However, complexation of chitosan with $\beta$-glycerophosphate ( $\beta$-GP) that is a polyol salt, could yield a thermosensitive in situ gel system. ${ }^{9.10}$ Apart from chitosan, poloxamers (Pluronics ${ }^{\circledR}$ ) are also employed in the preparation of thermosensitive in situ gels. Poloxamers are tri-block copolymers that exhibit amphiphilic nature attributed to hydrophilic polyethylene oxide (PEO) attached to central hydrophobic polypropylene oxide (PPO)." Poloxamers are available in various grades owing to different weight ratios of PEO and PPO. ${ }^{3}$ Among them, poloxamer 188 (P188) and poloxamer 407 (P407) grades are equally effective due to their safety in the ophthalmic region and clarity of their aqueous solution. "Hence, these grades were selected in this research to prepare thermosensitive in situ gels.

Despite the significant role of antibiotics and other antimicrobial agents for treating infectious diseases, side effects and emerging resistance have compromised their efficacy.12,13 Hence, this situation has called for urgent action to turn the search lights on the development of naturally derived novel bioactive antimicrobial compounds from plants to fight against new and re-emerging infectious diseases with greater efficacy, lower toxicity and resistance. Orthosiphon stamineus Benth. (OS, Lamiaceae), also known as "Misai Kucing", is a popular plant in the Southeast Asian and tropical countries including Malaysia for curbing various ailments such as diabetes, inflammations, abdominal pain, oedema, and gout. ${ }^{14}$ OS has been reported to be rich in phenolic bioactive compounds, namely rosmarinic acid (RA), sinensetin (SIN) and eupatorine, which present profoundly in the leaves of OS. ${ }^{15}$ OS extract loaded into ethosomal formulation using sophorolipid as a surfactant has exhibited anti-angiogenic and anti-melanoma effects in albino mice, after topical application. ${ }^{16}$ Hitherto, no published reports are available on the loading of OS extract into in situ gel formulation to evaluate the antimicrobial profile. Hence, this hypothesis-driven preliminary study was undertaken with objective of investigating the antimicrobial efficacy of OS extract-loaded thermosensitive in situ gelling systems against the selected pathogenic microorganisms responsible for various ocular infections.

\section{MATERIALS AND METHODS}

\section{Experimental part}

\section{Materials}

The dried leaves of OS were obtained from Ethno Resources (Malaysia). The standards of RA and SIN were purchased from Chemfaces (China). Chitosan, $\beta$-GP disodium salt, poloxamers and solvents including ethanol, methanol, acetonitrile, lactic acid, toluene, ethyl acetate, formic acid, and benzalkonium chloride (BAC) were purchased from Sigma-Aldrich, USA. Sodium chloride $(\mathrm{NaCl})$ was purchased from Friendemann Schmidt, Australia. Mueller-Hinton agar was procured from Oxoid, Hampshire, UK. All reagents and chemicals were used as received.

\section{Preparation of aqueous-ethanolic OS leaf extract}

An aliquot ( $50 \mathrm{~g}$ ) of dried OS leaves was blended (Waring $800 \mathrm{~S}$, USA) followed by maceration in $500 \mathrm{~mL}$ of ethanol-water (50:50) solvent (EWS) followed by filtration performed by a vacuum pump (Rocker 300, Malaysia). The evaporation of the filtrate was conducted using a rotary evaporator (Heidoph-36001270, Heidolph ${ }^{\top M}$, Germany) followed by lyophilization using a freeze dryer (Scanvac CoolSafe 9L, Denmark) for $48 \mathrm{~h}$. The crudedried extract was stored in a desiccator at ambient room temperature until further use.

\section{Thin layer chromatography (TLC)}

An extract of OS was dissolved in EWS to prepare standard solutions of 1,5 , and $10 \mathrm{mg} / \mathrm{mL}$, whilst the reference standards were RA and SIN which were dissolved in methanol [high performance liquid chromatography (HPLC) grade] to prepare a solution of $1 \mathrm{mg} / \mathrm{mL}$. The stationary phase was TLC plates $(20 \mathrm{~cm} \times 10 \mathrm{~cm}$ ) pre-coated with silica gel 60 F254 (E. Merck, Germany), whereas the mobile phase comprised ethyl acetate:toluene:formic acid at a ratio of 7:3:0.1, respectively.17 Following the air-drying of the TLC plate, images were taken under uv light at $254 \mathrm{~nm}$ and $366 \mathrm{~nm}$. The band separation was observed followed by the measurement of the retention factor $\left(R_{\mathrm{f}}\right)$ values of the compounds using the formula as given below. ${ }^{17}$

$\mathrm{Rf}=\frac{\text { Distance travelled by compound }}{\text { Distance travelled by solvent }}$ equation 1

Fingerprinting and quantification of aqueous-ethanolic OS extracts using HPLC

The test samples were prepared by dissolving $5 \mathrm{mg}$ of freezedried OS extract in $1 \mathrm{~mL}$ EWS followed by dilution to $1 \mathrm{mg} / \mathrm{mL}$. Standard solutions of RA and SIN at a strength of $0.5 \mathrm{mg} / \mathrm{mL}$ were prepared using methanol (HPLC grade) followed by serial dilutions to prepare a concentration range between 12.5 and $500 \mu \mathrm{g} / \mathrm{mL}$. An injection volume of $20 \mu \mathrm{L}$ was introduced into a C18 column $(5 \mu \mathrm{m}, 4.6 \mathrm{~mm} \times 250 \mathrm{~mm})$ in triplicate. The gradient mobile phase of $0.1 \%$ formic acid solution and acetonitrile (Table 1) was used at a flow rate of $1.5 \mathrm{~mL} / \mathrm{min}^{18}{ }^{18}$ The analysis was performed using HPLC (Agilent Technologies 1200, USA) 
at a detection wavelength of $320 \mathrm{~nm}$. The identification of RA and SIN in OS extracts was performed by comparing their $R_{t} s$ with those of standards. Quantification was performed using the peak area of chromatograms obtained.

Preparation of OS extract-loaded poloxamer and chitosanbased in situ gels

A cold dispersion method was employed to prepare poloxamerbased in situ gels. In this method, accurately weighed poloxamer grades P188 and P407 were dissolved in phosphate-buffered saline (PBS, $\mathrm{pH}$ 7.4) using a magnetic stirrer at $300 \mathrm{rpm}$ for $1 \mathrm{~h}$ followed by overnight refrigeration to allow complete hydration at $4^{\circ} \mathrm{C}$ (Table 2). OS extract along with $\mathrm{NaCl}$ and $\mathrm{BAC}$ was incorporated into hydrated formulation with constant stirring until a homogenous solution was seen. Chitosan-based in situ gels were fabricated by adding chitosan polymer $(1.5 \% \mathrm{w} / \mathrm{v})$ in lactic acid $(1.5 \% \mathrm{v} / \mathrm{v})$ with constant stirring at $300 \mathrm{rpm}$ to obtain a homogenous solution (Table 2 ). $\beta$-GP solutions $(10-50 \% \mathrm{w} / \mathrm{w}$ )

Table 1. Gradient elution system in separation of bioactive compounds present in OS extract

\begin{tabular}{lll} 
Time & 0.1\% Formic acid in water (\%) & Acetonitrile (\%) \\
\hline 0.01 & 95 & 5 \\
\hline 25.00 & 50 & 50 \\
\hline 26.00 & 20 & 80 \\
\hline 35.01 & 95 & 5 \\
\hline 45.00 & 95 & 5 \\
\hline
\end{tabular}

OS: Orthosiphon stamineus

Table 2. Composition of poloxamer and chitosan-based in situ gels loaded with OS extract

Poloxamer-based in situ gels containing OS extract

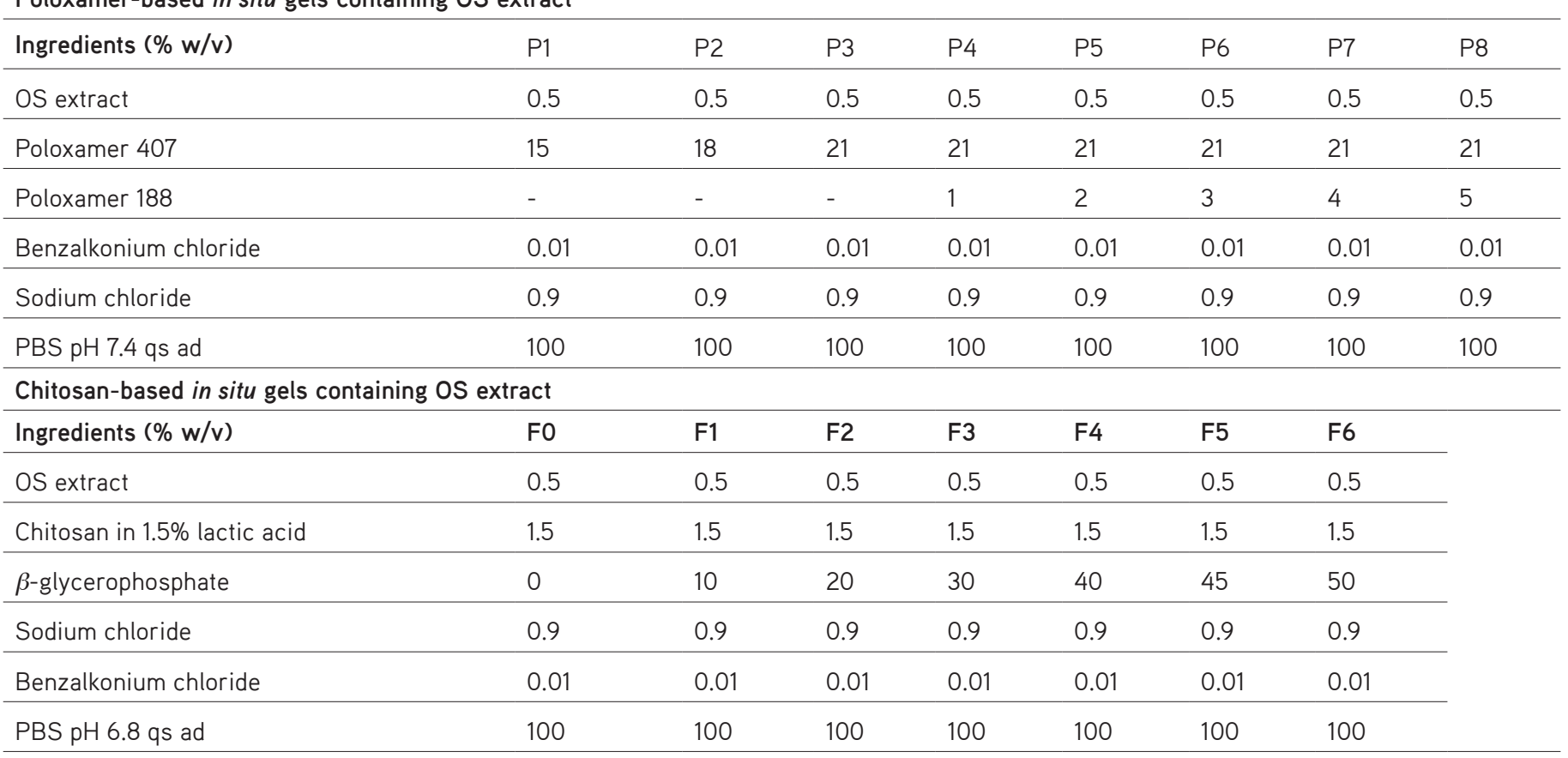

OS: Orthosiphon stamineus, PBS: Phosphate-buffered saline were formed using (PBS, $\mathrm{pH}$ 6.8) followed by overnight storage at $4^{\circ} \mathrm{C}$ overnight to get a clear solution. OS extract along with $\mathrm{NaCl}$ and $\mathrm{BAC}$ was incorporated into $\beta$-GP solution followed by constant stirring until a homogenous solution was obtained. This solution was incorporated dropwise into chitosan solution with constant stirring until a homogenous solution was obtained. All prepared formulations were subjected to storage at $4^{\circ} \mathrm{C}$ till required for use.

\section{Physicochemical characterization}

Physicochemical characterization of the preparation in situ gels was performed in terms of appearance, $\mathrm{pH}$, sol-to-gel transition temperature, and viscosity. ${ }^{3}$ The appearance of the in situ gels was observed against a background (black and white), while $\mathrm{pH}$ was determined using a pHmeter (EUTECH instrument, USA). To determine the temperature of sol-to-gel transition, solution form of in situ gel was transferred into an empty vial followed by immersing in a water bath adjusted initially at a temperature of $25^{\circ} \mathrm{C}$ followed by a gradual increase up to $50^{\circ} \mathrm{C}$. The vial was overturned frequently to observe the gel formation and the temperature of sol-to-gel transition was recorded once the solution converted into a complete gel with no flow upon wobbling of the vial. The viscosity of the in situ gel formulations before and after gelation was determined using a rheometer (Anton Paar, Stockholm, Sweden) spindle type CC17 at a speed between10 and 100 rpmi with a shear rate of 0-100 $\mathrm{mm} / \mathrm{s}$. To determine the suitable sterilization technique for the sterility of prepared in situ gels (P7 and F5 formulations), two sterilization methods, namely sterilization using an autoclave at $121^{\circ} \mathrm{C}$ for $15 \mathrm{~min}$ (Tomy SX-500, Japan) and sterilization using $0.20 \mu \mathrm{m}$ sterile regenerated cellulose syringe filters (Sartorius, Germany) under aseptic conditions were employed. 


\section{In vitro release of $R A$}

The in vitro release of RA was performed using dialysis membrane technique reported in our earlier publications with suitable modifications.,19 The first ever drawn schematic representation of dialysis membrane method that illustrates the in vitro RA-release measurement procedure in a step-bystep manner is shown in Figure 1. A dialysis membrane with a molecular weight cut-off of 3500 Da (Fisher Scientific, New Hampshire, USA) was soaked in the dissolution medium of simulated tear fluid (STF, pH 6.8) overnight. About $1 \mathrm{~mL}$ formulation was transferred into the dialysis bag, which was subsequently placed into a beaker filled with a $50 \mathrm{~mL}$ STF, $\mathrm{pH} 6.8$ and placed in a shaking water bath maintained at $37^{\circ} \mathrm{C}$ and $50 \mathrm{rpm}$. A fixed volume of $1 \mathrm{~mL}$ sample was taken at predetermined time intervals between 0.5 and $12 \mathrm{~h}$ followed by replacement with an equal amount of fresh STF to preserve the sink condition. RA released from in situ gels was analysed at a wavelength of $320 \mathrm{~nm}$ using ultraviolet (UV)-visible spectrophotometer (GENESYS ${ }^{\text {TM }} 10$, Thermo Scientific, USA). Percentage cumulative RA released versus time was plotted the drug release profile was characterized by estimating the time taken to release $50 \%$ of $\mathrm{RA}\left(\mathrm{t}_{50 \%}\right) .{ }^{20}$

\section{Antimicrobial efficacy of OS extract loaded in situ gels}

The antimicrobial efficacy of standardized aqueous-ethanolic OS leaf extracts loaded in situ gels against Gram-negative bacteria (Escherichia coli ATCC 10798 and Pseudomonas aeruginosa ATCC 9721) and Gram-positive bacteria (Micrococcus luteus ATCC 49732 and Staphylococcus aureus ATCC 6538) was determined using the agar well diffusion method. Autoclaved Mueller-Hinton agar (Oxoid, Hampshire, UK) was transferred into sterile petri dishes followed by inoculation using $100 \mu \mathrm{L}$

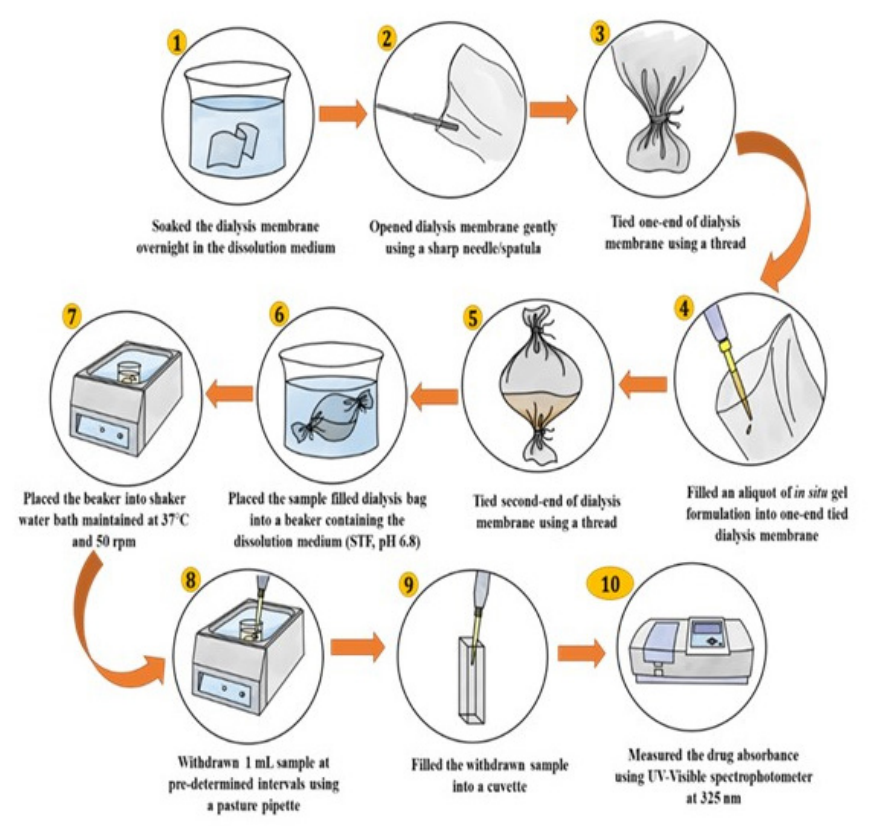

Figure 1. Schematic representation of in vitro release testing of RA from in situ gel formulations using dialysis membrane method

RA: Rosmarinic acid bacterial broth culture (0.5 McFarland standard). Agar wells (6 $\mathrm{mm}$ in diameter) were prepared using the tip of a sterile pasteur pipette followed by filling with $70 \mu \mathrm{L}$ tested OS extracts (0.5\% to $10 \%)$ and OS extracts loaded in situ gel formulations, respectively. RA ( $1 \mathrm{mg} / \mathrm{mL}$ ). Xepanicol ${ }^{\circledR}, 0.5 \%$ (chloramphenicol) and Ciplox ${ }^{\circledR}, 0.3 \%$ (ciprofloxacin) eye drops were employed as a positive control. The incubation of petri dishes was performed for $24 \mathrm{~h}$ at $37^{\circ} \mathrm{C}$ followed by the measurement of the resultant zones of inhibition (ZOI).

\section{Statistical analysis}

The results were evaluated statistically using one-way ANOVA followed by post hoc Tukey's test (GraphPad prism version 6.01, GraphPad software, La Jolla, California). The value $p<0.05$ was considered statistically significant difference.

\section{RESULTS}

\section{TLC and HPLC analyzes of OS EWS extracts}

OS EWS extract exhibited a percentage yield of $14.5 \%(\mathrm{w} / \mathrm{w})$ on a dry weight basis. TLC chromatograms demonstrated that both OS extract and reference standards (RA and SIN) exhibited same $R f$ values at 0.26 and 0.49 , respectively, when viewed under UV light at wavelengths of $254 \mathrm{~nm}$ (Figure 2a) and 366 $\mathrm{nm}$ (Figure $2 \mathrm{~b}$ ) confirming the presence of bioactive compounds RA and SIN. The HPLC chromatograms of reference standards (RA and SIN) and aqueous-ethanolic OS leaf extracts are shown in Figure 3. Both RA and SIN were eluted at the same retention times as of reference standards, RA (12.2 min) and $\mathrm{SIN}$ (20.7 min). A relatively higher content of RA (11.50 $\pm 0.23 \%$ $\mathrm{w} / \mathrm{w}$ ) was found in aqueous-ethanolic extract of OS leaves of $5 \mathrm{mg} / \mathrm{mL}$ compared to SIN $(0.88 \pm 0.02 \% \mathrm{w} / \mathrm{w})$. However, SIN was unquantifiable in aqueous-ethanolic OS extract of $1 \mathrm{mg} /$ $\mathrm{mL}$, whereas the content of RA was measured as $11.37 \pm 0.76 \%$ (w/w).

\section{Physicochemical characterization of in situ gel formulations} Except for formulation P3 prepared using 21\% P407, all in situ
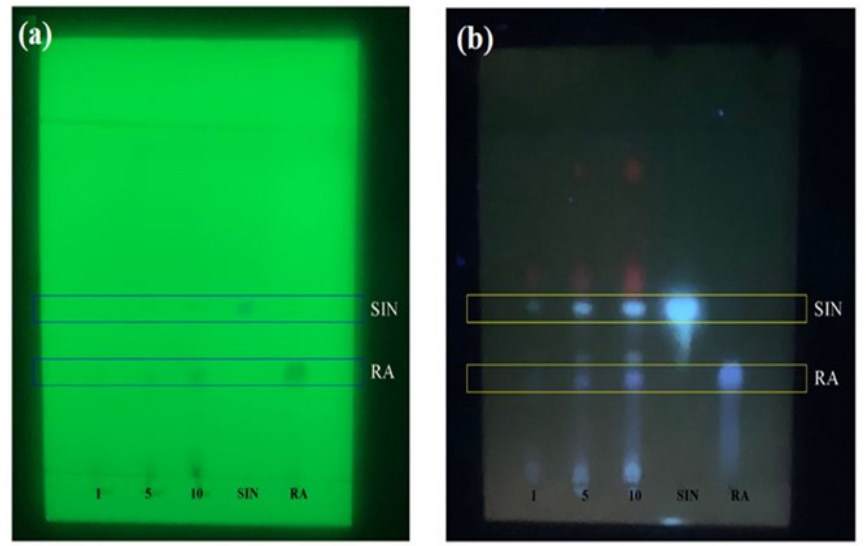

Figure 2. TLC chromatograms of the aqueous-ethanolic leaf extract of OS $(1 \mathrm{mg} / \mathrm{mL}, 5 \mathrm{mg} / \mathrm{mL}$ and $10 \mathrm{mg} / \mathrm{mL}$ ), and reference standards (RA and SIN) at $254 \mathrm{~nm}$ (a) and $366 \mathrm{~nm}$ (b)

TLC: Thin layer chromatography, RA: Rosmarinic acid, SIN: Sinensetin 
gel formulations were found to be clear, homogenous and free flowing solution with a brown colour, suggesting easy instillation into the eyes at an ambient room temperature (Table 3). The $\mathrm{pH}$ of poloxamer based in situ gels was in a range between 7.21 and 7.32. The sol-to-gel phase transition temperature of in situ gel formulations is depicted in Figure 4. In situ gels comprising
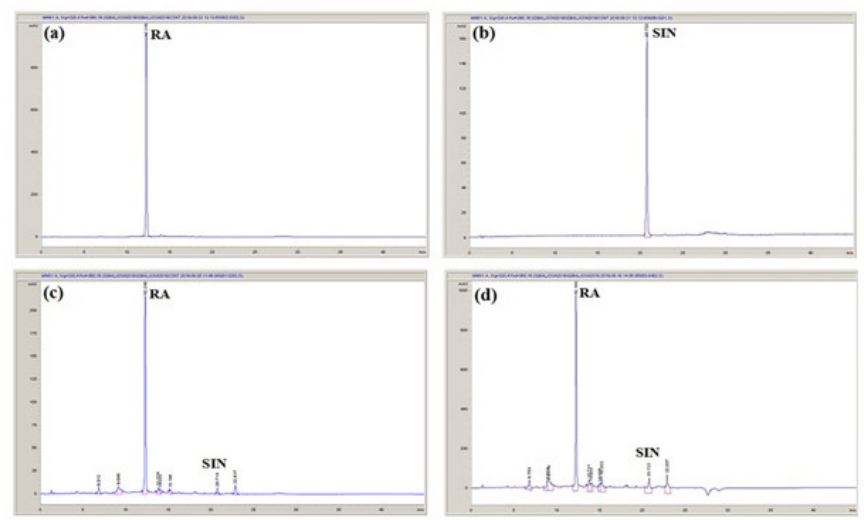

Figure 3. HPLC chromatograms of (a) standard RA at $t_{\mathrm{r}}: 12.215 \mathrm{~min}$; (b) standard SIN at $t: 20.720 \mathrm{~min}$; (c) aqueous-ethanolic leaf extract of OS (1 $\mathrm{mg} / \mathrm{mL}$ ) showing peaks corresponding to RA $\left(t_{r}: 12.243 \mathrm{~min}\right)$ and $\operatorname{SIN}\left(t_{r}\right.$ : $20.714 \mathrm{~min})$; (d) aqueous-ethanolic leaf extract of $O S(5 \mathrm{mg} / \mathrm{mL}$ ) showing peaks corresponding to RA $\left(t_{r}: 12.188 \mathrm{~min}\right)$ and $\operatorname{SIN}\left(t_{r}: 20.723 \mathrm{~min}\right)$

HPLC: High performance liquid chromatography, RA: Rosmarinic acid, SIN: Sinensetin, OS: Orthosiphon stamineus

merely of $\mathrm{P} 407$ at $21 \%(\mathrm{w} / \mathrm{v})$ content exhibited highest viscosity of $2440 \mathrm{mPas}$ at room temperature. Nevertheless, the introduction of P188 (1-5\%) at 21\% P407 caused a gradual reduction in the viscosity from 166 to $116 \mathrm{mPas}$ before gelation and increased viscosities from 337 to $5750 \mathrm{mPas}$ after the gelation (Table 3). Chitosan-based formulations demonstrated a substantial reduction in the viscosity from 25.9 to $11.5 \mathrm{mPas}$ before gelation and increased viscosity after gelation from 211
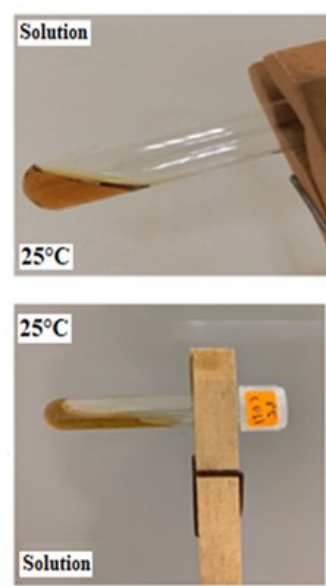

Figure 4. Depiction of sol-to-gel phase transition temperature of poloxamer-(a) and chitosan-(b) based in situ gels loaded with OS extract OS: Orthosiphon stamineus

Table 3. Physicochemical characterisation of poloxamer and chitosan based in situ gels loaded with OS extract (mean \pm SD, n: 3 )

Formulation code $\quad$ Appearance and clarity $\quad \mathrm{pH} \quad$ Sol-to-gel temperature $\left({ }^{\circ} \mathrm{C}\right)$

\section{Poloxamer-based in situ gel formulations}

\begin{tabular}{|c|c|c|c|c|c|}
\hline P1 & Clear and free flowing & $7.21 \pm 0.01$ & No gelation until $50^{\circ} \mathrm{C}$ & $27.30 \pm 0.38$ & - \\
\hline P2 & Clear and free flowing & $7.23 \pm 0.01$ & No gelation until $50^{\circ} \mathrm{C}$ & $58.01 \pm 0.46$ & - \\
\hline P3 & Clear and viscous (gel) & $7.29 \pm 0.01$ & $24.9 \pm 0.06$ & $2440.00 \pm 17.52$ & - \\
\hline P4 & Clear and free flowing & $7.32 \pm 0.01$ & $27.9 \pm 0.10$ & $166.18 \pm 3.15$ & $337.52 \pm 4.16$ \\
\hline P5 & Clear and free flowing & $7.30 \pm 0.01$ & $31.5 \pm 0.21$ & $150.37 \pm 2.66$ & $319.81 \pm 2.43$ \\
\hline P6 & Clear and free flowing & $7.22 \pm 0.01$ & $32.9 \pm 0.36$ & $138.25 \pm 2.01$ & $1280.16 \pm 8.66$ \\
\hline P7 & Clear and free flowing & $7.27 \pm 0.01$ & $33.6 \pm 0.10$ & $125.09 \pm 2.45$ & $3510.34 \pm 11.02$ \\
\hline P8 & Clear and free flowing & $7.30 \pm 0.01$ & $34.9 \pm 0.12$ & $116.01 \pm 3.38$ & $5750.47 \pm 18.49$ \\
\hline \multicolumn{6}{|c|}{ Chitosan-based in situ gel formulations } \\
\hline FO & Clear and free flowing & $4.56 \pm 0.01$ & No gelation until $50^{\circ} \mathrm{C}$ & $26.30 \pm 0.77$ & - \\
\hline $\mathrm{F} 1$ & Clear and free flowing & $7.09 \pm 0.01$ & No gelation until $50^{\circ} \mathrm{C}$ & $58.90 \pm 1.23$ & - \\
\hline $\mathrm{F} 2$ & Clear and free flowing & $7.28 \pm 0.01$ & No gelation until $50^{\circ} \mathrm{C}$ & $77.96 \pm 1.84$ & - \\
\hline F3 & Clear and free flowing & $7.41 \pm 0.01$ & $40.3 \pm 1.27$ & $25.90 \pm 1.35$ & $211.00 \pm 4.81$ \\
\hline $\mathrm{F} 4$ & Clear and free flowing & $7.37 \pm 0.01$ & $38.7 \pm 0.85$ & $14.75 \pm 0.81$ & $126.81 \pm 3.42$ \\
\hline F5 & Clear and free flowing & $7.46 \pm 0.01$ & $34.5 \pm 0.07$ & $12.37 \pm 0.35$ & $120.00 \pm 6.19$ \\
\hline F6 & Clear and free flowing & $7.47 \pm 0.01$ & $32.4 \pm 0.71$ & $11.50 \pm 0.18$ & $111.57 \pm 5.05$ \\
\hline
\end{tabular}

Viscosity (mPas)

Before gelation After gelation

Before gelation After gelation

SD: Standard deviation, OS: Orthosiphon stamineus 
to $111 \mathrm{mPas}$ with an increased $\beta$-GP concentration from 30 to $50 \%$ (F3-F6). The two sterilization methods employed did not affect the appearance, flow property, sol-to-gel temperature and viscosity results, however compared with autoclave sterilization, syringe filter sterilization demonstrated a small reduction of 0.1 unit in $\mathrm{pH}$ value. Additionally, the sterilized P7 and $\mathrm{F} 5$ in situ gel formulations exhibited increased RA content (47.67\% and $45.13 \%)$ and reduced RA content $(6.23 \%$ and $5.39 \%)$ following the sterilization using autoclave and filtration techniques, respectively, in comparison to the freshly prepared in situ gels.

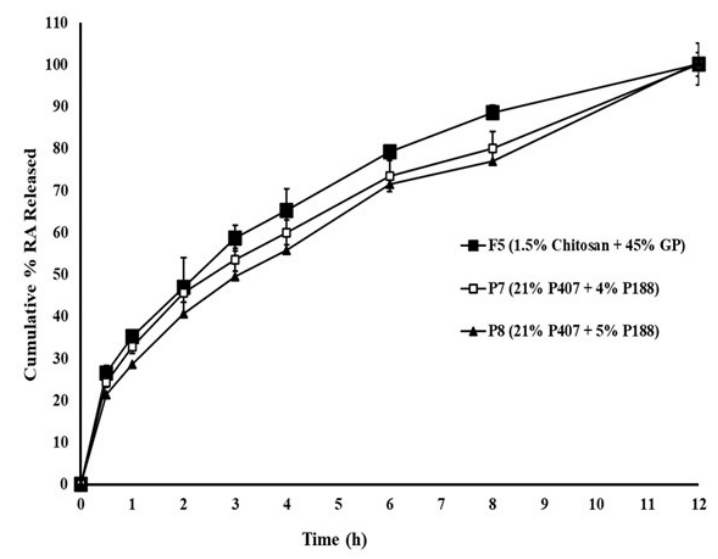

Figure 5. In vitro release profile of RA from chitosan (F5) and poloxamer (P7 and P8)-based in situ gel formulations (mean \pm standard deviation, $\mathrm{n}: 3$ ) RA: Rosmarinic acid

Table 4. ZOI of the tested samples against Gram-positive and negative bacteria

\begin{tabular}{|c|c|c|c|c|}
\hline \multirow{3}{*}{ Treatments } & \multicolumn{4}{|c|}{$\mathrm{ZOI}(\mathrm{mm})$, mean \pm SD $(\mathrm{n}: 3)$} \\
\hline & \multicolumn{2}{|c|}{ Gram-positive bacteria } & \multicolumn{2}{|c|}{ Gram-negative bacteria } \\
\hline & Micrococcus luteus & Staphylococcus aureus & Escherichia coli & Pseudomonas aeruginosa \\
\hline 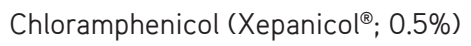 & $42.3 \pm 1.5^{\mathrm{a}}$ & $26.0 \pm 1.0^{\mathrm{a}}$ & $29.7 \pm 0.6^{b}$ & $24.7 \pm 0.6^{a}$ \\
\hline Ciprofloxacin (Ciplox ${ }^{\circledR} ; 0.3 \%$ ) & $32.7 \pm 1.2^{b}$ & $26.3 \pm 1.2^{\mathrm{a}}$ & $33.3 \pm 0.6^{a}$ & $20.3 \pm 1.5^{b}$ \\
\hline Standard RA (1 mg/mL) & $3.0 \pm 1.0^{d}$ & $1.3 \pm 0.6^{e}$ & $3.0 \pm 0.0^{c}$ & $4.7 \pm 0.6^{c}$ \\
\hline F5 (0.5\%) & $4.3 \pm 2.1^{d}$ & $0.0 \pm 0.0^{\mathrm{e}}$ & NT & $0.0 \pm 0.0^{\mathrm{d}}$ \\
\hline P7 (0.5\%) & $0.0 \pm 0.0^{e}$ & $0.0 \pm 0.0^{e}$ & $0.0 \pm 0.0^{e}$ & $0.0 \pm 0.0^{d}$ \\
\hline P7 (1\%) & $0.0 \pm 0.0^{e}$ & $0.3 \pm 0.6^{\mathrm{e}}$ & $0.0 \pm 0.0^{e}$ & $0.0 \pm 0.0^{d}$ \\
\hline P8 (0.5\%) & $0.0 \pm 0.0^{e}$ & $0.0 \pm 0.0^{e}$ & $0.0 \pm 0.0^{e}$ & $0.0 \pm 0.0^{d}$ \\
\hline P8 (1\%) & $0.0 \pm 0.0^{e}$ & $0.3 \pm 0.6^{\mathrm{e}}$ & $0.0 \pm 0.0^{e}$ & $0.0 \pm 0.0^{d}$ \\
\hline E0.5\% & $3.3 \pm 0.6^{d}$ & $0.0 \pm 0.0^{e}$ & $0.0 \pm 0.0^{e}$ & $0.0 \pm 0.0^{d}$ \\
\hline $\mathrm{E} 1 \%$ & $4.3 \pm 0.6^{d}$ & $0.0 \pm 0.0^{\mathrm{e}}$ & $0.0 \pm 0.0^{\mathrm{e}}$ & $0.0 \pm 0.0^{d}$ \\
\hline E3\% & $15.3 \pm 0.6^{c}$ & $4.3 \pm 0.6^{d}$ & $0.0 \pm 0.0^{e}$ & $0.0 \pm 0.0^{d}$ \\
\hline $\mathrm{E} 5 \%$ & $16.0 \pm 1.0^{c}$ & $6.7 \pm 0.6^{c}$ & $1.7 \pm 0.6^{d}$ & $0.0 \pm 0.0^{d}$ \\
\hline $\mathrm{E} 10 \%$ & $16.0 \pm 1.0^{c}$ & $9.3 \pm 0.6^{b}$ & $3.3 \pm 0.6^{c}$ & $0.0 \pm 0.0^{d}$ \\
\hline
\end{tabular}

a-e Different letters represent significant differences $(p<0.05)$ between treatments. NT: Not tested, ZOI: Zones of inhibition, SD: Standard deviation,

RA: Rosmarinic acid

\section{In vitro release study of $R A$}

Based on the physicochemical characterization especially solto-gel temperature findings, F5, P7, and P8 formulations were preferred for in vitro RA release and antimicrobial efficacy investigations. The in vitro release of RA from chitosan- $\beta$ GP and poloxamer-based in situ gel formulations are depicted in Figure 5. A substantial burst release of $35 \%, 32.81 \%$, and $28.73 \%$ within the first $60 \mathrm{~min}$ and after that a gradual and complete RA release in a sustained manner for a period of $12 \mathrm{~h}$ was observed from F5, P7, and P8 formulations, respectively.

Antimicrobial efficacy of standardized aqueous-ethanolic OS leaf extracts loaded in situ gel formulations

Table 4 and Figure 6 show the ZOI of the tested samples against the Gram-positive and negative bacteria. Formulation F5 loaded with $0.5 \%(\mathrm{w} / \mathrm{v})$ OS extract exhibited a modest antimicrobial efficacy against Gram-positive M. luteus ( $\mathrm{ZOI}: 4.3 \mathrm{~mm}$ ). However, it was, inactive against $S$. aureus and $P$. aeruginosa. To further test the antimicrobial efficacy of OS extract, the loading concentration of $\mathrm{OS}$ extract in P7 and P8 formulations was increased from $0.5 \%$ to $1 \%(\mathrm{w} / \mathrm{v})$. However, both formulations were also found to be inactive against all tested bacteria (ZOI: $0.3 \mathrm{~mm}$ against $S$. aureus). Subsequent tests, which involved the use of OS leaf extracts at $0.5-10 \%$ (i.e., E0.5-10\%) yielded a concentration-dependent antimicrobial activity against all tested bacteria except $P$. aeruginosa. The extracts, especially $\mathrm{E} 5 \%$ and $\mathrm{E} 10 \%$, were most active against $M$. luteus (highest ZOI: $16.0 \mathrm{~mm}$ ), followed by $S$. aureus (highest ZOI: $9.3 \mathrm{~mm}$ ) and $E$. coli (highest ZOI: $3.3 \mathrm{~mm}$ ). As expected, reference products (i.e., positive controls), chloramphenicol (Xepanicol ${ }^{\circledR}$, $0.5 \%$ ) and ciprofloxacin (Ciplox ${ }^{\circledR}, 0.3 \%$ ) elicited very active

\section{T.5\%) and}

$\mathrm{ZOI}(\mathrm{mm})$, mean \pm SD (n: 3) 


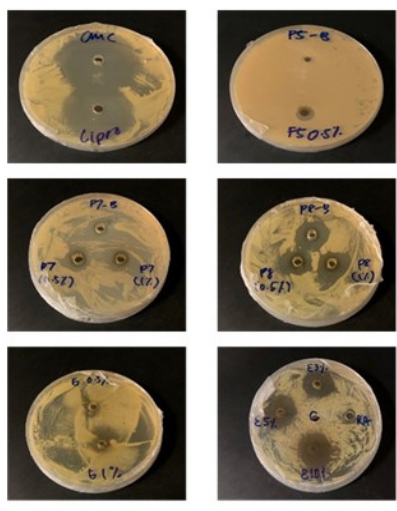

(a) M. luteus
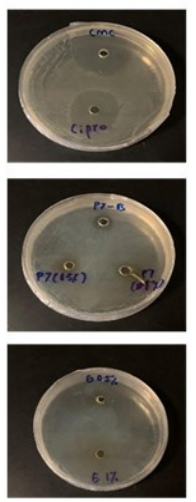

(c) P. aeruginosa
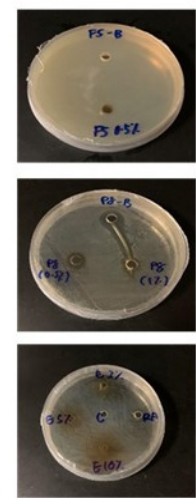
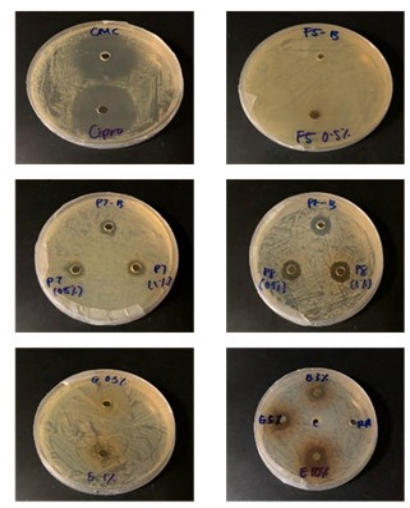

(b) S. aureus

Figure 6. Representative images indicating $\mathrm{ZOI}$ of the tested samples against Gram-positive bacteria (a) Micrococcus luteus; (b) Staphylococcus aureus and Gram-negative bacteria (c) Pseudomonas aeruginosa; (d) Escherichia coli

ZOI: Zones of inhibition

antimicrobial efficacy against all tested bacteria ( $\mathrm{ZOI} \geq 20.3$ $\mathrm{mm}$ ). The standard RA, on the other hand, produced a modest antimicrobial activity, when tested against both Gram-positive and negative bacteria at $1 \mathrm{mg} / \mathrm{mL}$ ( $\mathrm{ZOI} \leq 4.7 \mathrm{~mm}$ ).

\section{DISCUSSION}

The extraction of OS leaves was successfully with a percentage yield of approximately $14.5 \%(\mathrm{w} / \mathrm{w})$ on a dry weight basis, which was consistent with an earlier reported study. ${ }^{21}$ TLC analysis of OS extract exhibited robust band separation of the intended bioactive compounds, namely RA and SIN and these results are in agreement with a previous study. ${ }^{17}$ Also, considerable amount of RA $(11.5 \%, w / w)$ was quantified by HPLC analysis of OS extract at $5 \mathrm{mg} / \mathrm{mL}$, which is primarily accountable for the antimicrobial activity of OS extract. ${ }^{14}$ The use of water and ethanol binary mixture at 50:50 ratio as a solvent extract yielded a high content of phenolic compounds including RA. ${ }^{22}$

Apart from formulation F1 ( $0 \% \beta$-GP), chitosan and $\beta$-GP based in situ gel formulations were homogenous, clear, and with $\mathrm{pH}$ values within a range of 6.8-7.4, ideal for the ophthalmic tissues depicting that in situ gels were non-irritating to eye. ${ }^{23}$ All chitosan-based in situ gel formulations exhibited low viscosity at $25^{\circ} \mathrm{C}$ pivotal for their existence in the solution form to ease the expulsion from the eye drop container. ${ }^{3}$ Increasing the $\beta$-GP concentration from $10 \%$ to $50 \%(\mathrm{w} / \mathrm{v})$ led to a further reduction in the viscosity $(p<0.05)$, which could be ascribed to the attachment of the amine group of chitosan with the phosphate group of the $\beta$-GP. ${ }^{24}$ The sol-to-gel transition temperature of these formulations dropped significantly to $32.4^{\circ} \mathrm{C}$ from $38.7^{\circ} \mathrm{C}$ upon increasing the $\beta$-GP concentrations from 30 to $50 \%$ (w/w). In the absence of $\beta$-GP, chitosan did not exhibit sol-to-gel phase transition (formulation FO) indicating the thermal insensitivity of chitosan to the surrounding temperature. Interestingly, only F5 ( $1.5 \%$ chitosan and $45 \% \beta-\mathrm{GP}, \mathrm{w} / \mathrm{v})$ transformed into gel at the temperature range between $33^{\circ} \mathrm{C}$ and $37^{\circ} \mathrm{C}$ that might be attributable to the enhancement in hydrogen bonding among chitosan chains upon a rise in temperature rise leading to gelation. ${ }^{25}$ This gelation caused an enhancement in viscosity to $120 \mathrm{mPas}$ from $12.3 \mathrm{mPas}$ before gelation, which aided in increasing the reside time of formulation at pre-corneal surface. ${ }^{19}$ Based on the ideal characteristics of in situ gels, formulation F5 was selected for further evaluation in terms of in vitro release and the antimicrobial activity.

Except for P3 (P407 at 21\% w/v), poloxamer-based in situ gels were clear, homogenous, and free-slowing at $25^{\circ} \mathrm{C}$, whilst P3 formed viscous gels even at room temperature (Table 3 ). This was not surprising as it was reported that $\mathrm{P} 407$ would form a gel at an ambient room temperature at content above $20 \%(\mathrm{w} / \mathrm{v})$ solto-gel and that the gelation phenomenon is reversible. ${ }^{26,27} \mathrm{The} \mathrm{pH}$ of all poloxamer-based formulations was within a limit pivotal for ocular surface and suitable for ocular application without any irritation. ${ }^{28}$ The viscosity of poloxamer-based formulations was significantly enhanced by increasing P407 concentration to $21 \%(w / v)$. Apart from P5, a significant increase in the viscosity of in situ gels from 337 to 5750 mPas after gelation was observed, when compared to before gelation at room temperature $(p<0.05)$. These findings were in agreement with a previous report stating that the size and number of micelles within gel increase with a rise in the polymer concentration, which after that leads to enhanced cross-link between micelles by shortening the inter-micellar distance, resulting in the formation of three-dimensional gel structure with higher viscosity. ${ }^{29}$ Among all, P7 and P8 formulations demonstrated the highest viscosities upon transition into a gel. An optimum in situ gel must exhibit sol-gel transition at a temperature above $25^{\circ} \mathrm{C}$; but below the temperature of eye surface $\left(33-37^{\circ} \mathrm{C}\right.$. Nonetheless, increasing the concentration of P407 from 18\% to $21 \%(\mathrm{w} / \mathrm{v})$, led to the incapability to undergoing gelation until $50^{\circ} \mathrm{C}$ and formulation P3 was formed a gel-like structure at room temperature. This is attributed to the formation of additional micelles at P407 concentration above its critical micelle concentration, which reduced energy required for endothermic micellar crystallization and consequently sol-gel temperature was decreased. ${ }^{30}$ Nonetheless, an addition of P188 at content between 1 and $5 \%(\mathrm{w} / \mathrm{w})$ enhanced the sol-to-gel transition temperature for the subsequent formulations (P4-P9) to $34.9^{\circ} \mathrm{C}$ from $27.9^{\circ} \mathrm{C}$. This is ascribable to the disruption in the formation of P407 micelles upon incorporation of hydrophilic 
P188 leading to accumulation of excessive water in the proximity of hydrophobic PPO units of P407. This could have increased the required energy to initiate hydrophobic interactions among P407 micelles and consequently increased the temperature of sol-gel transition. ${ }^{26}$ Only P7 and P8 formulations demonstrated optimum $\mathrm{pH}$ and phase transition at ocular temperature and, hence, were chosen for further studies.

Autoclave-sterilization dramatically increased the content of phenolic compound, RA, to almost double with respect to the freshly prepared and unsterilized in situ gel formulations. This could be ascribed to the heat employed during the autoclave process $\left(121^{\circ} \mathrm{C}\right.$ ), which promoted the release of phenolic compounds due to breakdown of cell walls and cellular components. The dissociation of conjugated polyphenols such as tannins to simpler phenolic compounds due to the thermal process could have also contributed to the increased amount of RA. ${ }^{31}$ The attained results are in similar agreement with the previously reported literature on the sterilization effect on the bioactive compounds present in the natural plant extracts. ${ }^{32,33}$ The sterilization of in situ gel formulations by filtration technique demonstrated a small decrease in the RA content, which might be due to the sorption, where the substance is adsorbed onto the filter at the solid-liquid interface and removes the active constituent from the formulation. ${ }^{34}$ Besides, the filtration of in situ gel formulations through $0.2 \mu \mathrm{m}$ was found to be cumbersome due to the slightly viscous nature of the formulations because of the presence of poloxamer and chitosan polymeric content. Hence, this study confirms that autoclave sterilization is a suitable technique for the sterility of in situ gels as it did not exert any negative effect on the formulation characteristics and rather increased the content of RA, which could aid in further enhancing the antimicrobial efficacy of the prepared formulations.

The in vitro release studies of RA from the optimization in situ gel formulations demonstrated an initial burst release at first hour followed by a gradual and sustained release for $12 \mathrm{~h}$, which is pivotal for the effective treatment of ocular infections. The $t_{50 \%}$ of the formulations F5, P7, and P8 were found to be 2.26 h, $2.55 \mathrm{~h}$, and $3.06 \mathrm{~h}$, respectively. No statistically significant differences ( $p>0.05$ ) between the release profiles of RA from F5, P7, and P8 in terms of $t_{50 \%}$ values were found, suggesting a closely similar in vitro-release profiles. ${ }^{20}$ The sustained release of RA from formulation F5 was attributed to chitosan polymer in the in situ gelling system capable of not only enhancing the viscosity of the formulation but also strong adhesion to the mucous layer of the precorneal area. ${ }^{8}$ The sustained delivery of RA from poloxamer-based formulations might be attributed to enhanced rheological properties of formulations after gelation, which led the formation of tightly packed micellar structure, while initiating increased intermolecular interactions in the in situ gelling system. ${ }^{35}$

The chitosan-based in situ gel formulation (F5) loaded with $0.5 \%(\mathrm{w} / \mathrm{v})$ OS extract exhibited modest antimicrobial activity against Gram-positive M. luteus. However, poloxamer-based in situ gel formulations, P7 and P8, loaded with either $0.5 \%(\mathrm{w} / \mathrm{v})$ or $1 \%(\mathrm{w} / \mathrm{v})$ OS extracts and, however, were inactive against all tested bacteria. Subsequently, the resultant antimicrobial activity of OS extract at concentrations ranging between $0.5 \%$ $10 \%(\mathrm{w} / \mathrm{v})$ indicated a concentration-dependent antimicrobial activity against all tested bacteria except $P$. aeruginosa. The antimicrobial activity of OS is attributed primarily to the pro-oxidative properties of the RA. ${ }^{36}$ Additionally, RA could also induce bacterial cell death by altering the charge and hydrophobicity of the bacterial membrane surface. ${ }^{37}$ The present findings indicated OS extract, especially E5\% and $\mathrm{E} 10 \%$, to be the most active against M. luteus. This agrees with previous findings documenting the partial to full effectiveness of OS extracts against Gram-positive bacteria, especially $M$. luteus, at a concentration above $3 \%{ }^{38}$ The ineffectiveness of OS extract against Gram-negative bacteria, was also consistent with the previously reported findings. ${ }^{39}$ This could be ascribed to an additional fortification for the microorganisms provided by extra outer membrane. ${ }^{40}$ An attempt to incorporate $5-10 \%$ $(\mathrm{w} / \mathrm{v})$ OS extract into in situ gels resulted in dark-colored formulations with insoluble sediments. This could be due to the presence of an elevated content of lipophilic compounds in the OS extract. ${ }^{41}$ Dark-coloured formulations could impair vision and mitigate the treatment adherence because clarity is a pivotal characteristic of any ocular formulation..$^{42}$ Nevertheless, the solubility of OS extract at relatively higher concentrations in the in situ gel formulation could be enhanced using various methods such as particle size reduction, inclusion of surfactants and complexation. 43,44 Moreover, purified RA isolated from OS extracts might also demonstrate promising antimicrobial activity.

\section{Study limitations}

The OS extract exhibited a moderate antimicrobial activity indicating concentration-dependent improvement against the antimicrobial activity especially against Gram-positive bacteria. Nonetheless, elevating the content of OS extract in the in situ gelling system resulted in dark-coloured sediments. This raises the need for further research to improve the clarity of in situ gel formulations loaded with OS extract at high concentrations. Further research is also recommended for isolation of RA from OS extract before incorporation into in situ gels for achieving a potential antimicrobial activity.

\section{CONCLUSION}

Standardized aqueous-ethanolic leaf extract of OS was obtained successfully using water: Ethanol binary mixture (50:50) as solvent via a maceration method. The presence of bioactive phenolic compounds, namely RA and SIN, in the OS extract was confirmed through TLC and HPLC methods. The optimized thermosensitive poloxamer and chitosan-based in situ gels loaded with OS extract, P7, P8, and F5 demonstrated a $\mathrm{pH}$ and sol-to-gel temperature suitable for ocular region. Additionally, release of RA was sustained up to a period of 12 h. Sterilization by autoclave was found to be a better technique than sterilization by filtration for achieving the sterility of in situ gel formulations. Formulation F5 loaded with $0.5 \%$ OS extract exhibited modest antimicrobial activity against $M$. 
luteus, which appeared to be concentration dependent and indicated that increasing OS extract to $10 \%(\mathrm{w} / \mathrm{v})$ may improve the antimicrobial activity, especially against Gram-positive bacteria. However, high concentrations of OS extract in the in situ gelling system-induced dark-coloured sediments. In conclusion, preliminary findings of this study could serve as a new source in race to find novel plant-derived antimicrobial compounds to fight against the new and re-emerging infections caused by antibiotic-resistant pathogens that is posing an alarming concern across the globe.

\section{Ethics}

Ethics Committee Approval: This study does not involve any animal or human subjects and hence ethics committee approval was not required.

Informed Consent: Not applicable.

Peer-review: Externally peer-reviewed.

\section{Authorship Contributions}

Concept: F.Z., R.S., Design: F.Z., R.S., K.R., Data Collection or Processing: N.Z.W., I.D.S., K.A., Analysis or Interpretation: F.Z., R.S., S.M.L., Literature Search: N.Z.W., I.D.S., Writing: F.Z., R.S.

Conflict of Interest: No conflict of interest was declared by the authors.

Financial Disclosure: The authors want to thank International Medical University, Malaysia for providing the research grant (BP 1-01-2019 (37) and the Faculty of Pharmacy, Universiti Teknologi MARA, Selangor branch, Puncak Alam Campus, Malaysia for providing the necessary lab space and facilities to conduct this work.

\section{REFERENCES}

1. Song HY, Qiu BF, Liu C, Zhu SX, Wang SC, Miao J, Jing J, Shao YX. Identification of causative pathogens in mouse eyes with bacterial keratitis by sequence analysis of 16S rDNA libraries. Exp Anim. 2015;64:49-56.

2. Yeu E, Hauswirth S. A review of the differential diagnosis of acute infectious conjunctivitis: implications for treatment and management. Clin Ophthalmol. 2020;14:805-813.

3. Sheshala R, Quah SY, Tan GC, Meka VS, Jnanendrappa N, Sahu PS. Investigation on solution-to-gel characteristic of thermosensitive and mucoadhesive biopolymers for the development of moxifloxacinloaded sustained release periodontal in situ gels. Drug Deliv Transl Res. 2019;9:434-443.

4. Song Y, Nagai N, Saijo S, Kaji H, Nishizawa M, Abe T. In situ formation of injectable chitosan-gelatin hydrogels through double crosslinking for sustained intraocular drug delivery. Mater Sci Eng C Mater Biol Appl. 2018;88:1-12.

5. Cheng YH, Tsai TH, Jhan YY, Chiu AW, Tsai KL, Chien CS, Chiou SH, Liu CJ. Thermosensitive chitosan-based hydrogel as a topical ocular drug delivery system of latanoprost for glaucoma treatment. Carbohydr Polym. 2016;144:390-399.

6. Gupta H, Aqil M, Khar RK, Ali A, Bhatnagar A, Mittal G. An alternative in situ gel-formulation of levofloxacin eye drops for prolong ocular retention. J Pharm Bioallied Sci. 2015;7:9-14.
7. Cho MH, Kim KS, Ahn HH, Kim MS, Kim SH, Khang G, Lee B, Lee HB. Chitosan gel as an in situ-forming scaffold for rat bone marrow mesenchymal stem cells in vivo. Tissue Eng Part A. 2008;14:1099-1108.

8. Gupta H, Jain S, Mathur R, Mishra P, Mishra AK, Velpandian T. Sustained ocular drug delivery from a temperature and $\mathrm{pH}$ triggered novel in situ gel system. Drug Deliv. 2007;14:507-515.

9. Zhou HY, Jiang LJ, Cao PP, Li JB, Chen XG. Glycerophosphate-based chitosan thermosensitive hydrogels and their biomedical applications. Carbohydr Polym. 2015;117:524-536.

10. Wu G, Yuan Y, He J, Li Y, Dai X, Zhao B. Stable thermosensitive in situ gel-forming systems based on the lyophilizate of chitosan $/ \alpha, \beta$ glycerophosphate salts. Int J Pharm. 2016;511:560-569.

11. Soliman KA, Ullah K, Shah A, Jones DS, Singh TRR. Poloxamer-based in situ gelling thermoresponsive systems for ocular drug delivery applications. Drug Discov Today. 2019;24:1575-1586.

12. Ifeanyichukwu I, Chika E, Ogonna A, Chidinma I, Monique A, Ikechukwu M, Stanley E, Emmanuel N, Ngozi A, Agabus N. Prevalence and antibiogram of Salmonella species isolated from poultry products. J Adv Vet Anim Res. 2016;3:353-359.

13. Burman S, Bhattacharya K, Mukherjee D, Chandra G. Antibacterial efficacy of leaf extracts of Combretum album Pers. against some pathogenic bacteria. BMC Complement Altern Med. 2018;18:213.

14. Alshawsh MA, Abdulla MA, Ismail S, Amin ZA, Qader SW, Hadi HA, Harmal NS. Free radical scavenging, antimicrobial and immunomodulatory activities of Orthosiphon stamineus. Molecules. 2012;17:5385-5395.

15. Romulo A, Zuhud EAM, Rondevaldova J, Kokoska L. Screening of in vitro antimicrobial activity of plants used in traditional Indonesian medicine. Pharm Biol. 2018;56:287-293.

16. Vishkaei MN, Ahamed Basheer MK, Abdul Majid AMS. In vivo melanoma tumor study of ethosomal formulation composed of standardized Orthosiphon stamineus extract and sophorolipid. J Angiotherapy. 2019. doi.org/10.25163/ angiotherapy.1120591141830219

17. Hashim S, Beh HK, Hamil MS, Ismail Z, Majid AM. High-performance thinlayer chromatography method development, validation, and simultaneous quantification of four compounds identified in standardized extracts of Orthosiphon stamineus. Pharmacognosy Res. 2016;8:238-243.

18. Globinmed - Orthosiphon aristatus (Blume) Miq. Published 2019. Accessed date: September 04,2021. Available from: https://www. globinmed.com/index.php?option=com_content\&view=article\&id=10197 2:orthosiphon-stamineus-benth\&catid=209\&ltemid=143Globinmed

19. Sheshala R, Ming NJ, Kok YY, Singh TRR, Dua K. Formulation and characterization of $\mathrm{pH}$ induced in situ gels containing sulfacetamide sodium for ocular drug delivery: a combination of Carbopo ${ }^{\circledast} / \mathrm{HPMC}$ polymer. Indian J Pharm Educ Res. 2019;53:654-662.

20. Zeeshan F, Lin PY, Sheshala R. Application of similarity factor (F2) and time required to drug release ( $t \%)$ indicators for dissolution profiles comparison of paracetamol tablets. Indian J Pharm Educ Res. 2020;54:647-653.

21. Mohamed EA, Siddiqui MJ, Ang LF, Sadikun A, Chan SH, Tan SC, Asmawi MZ, Yam MF. Potent $\alpha$-glucosidase and $\alpha$-amylase inhibitory activities of standardized $50 \%$ ethanolic extracts and sinensetin from Orthosiphon stamineus Benth as anti-diabetic mechanism. BMC Complement Altern Med. 2012;12:176.

22. Khaw KY, Parat MO, Shaw PN, Falconer JR. Solvent supercritical fluid technologies to extract bioactive compounds from natural sources: a review. Molecules. 2017;22:1186. 
23. Huang W, Zhang N, Hua H, Liu T, Tang Y, Fu L, Yang Y, Ma X, Zhao Y. Preparation, pharmacokinetics and pharmacodynamics of ophthalmic thermosensitive in situ hydrogel of betaxolol hydrochloride. Biomed Pharmacother. 2016;83:107-113.

24. Pereira RM, Andrade GSS, De Castro HF, Campos MGN. Performance of chitosan/glycerol phosphate hydrogel as a support for lipase immobilization. Materials Res. 2017;20(Suppl 2):190-201.

25. Huang $\mathrm{CL}$, Chen YB, Lo YL, Lin YH. Development of chitosan/ $\beta$ glycerophosphate/glycerol hydrogel as a thermosensitive coupling agent. Carbohydr Polym. 2016;147:409-414.

26. Asasutjarit R, Thanasanchokpibull S, Fuongfuchat A, Veeranondha S. Optimization and evaluation of thermoresponsive diclofenac sodium ophthalmic in situ gels. Int J Pharm. 2011;411:128-135.

27. Fakhari A, Corcoran M, Schwarz A. Thermogelling properties of purified poloxamer 407. Heliyon. 2017;3:e00390.

28. Lim LT, Ah-Kee EY, Collins CE. Common eye drops and their implications for $\mathrm{pH}$ measurements in the management of chemical eye injuries. Int $\mathrm{J}$ Ophthalmol. 2014;7:1067-1068.

29. El-Kamel $\mathrm{AH}$. In vitro and in vivo evaluation of Pluronic F127-based ocular delivery system for timolol maleate. Int J Pharm. 2002;241:47-55.

30. Zhang M, Djabourov M, Bourgaux C, Bouchemal K. Nanostructured fluids from Pluronic ${ }^{\circledR}$ mixtures. Int J Pharm. 2013;454:599-610.

31. Terrazas-Hernández J, Santos-López EM, Cariño-Cortés R, JiménezAlvarado R, López-Palestina CU, Hernández-Fuentes AD. Effects of sterilization on bioactives of Jatropha dioica and Opuntia oligacantha extracts, and on antimicrobial capacity against Streptococcus. Appl Sci. 2018;8:2516.

32. Harjanti DW, Wahyono F, Ciptaningtyas VR. Effects of different sterilization methods of herbal formula on phytochemical compounds and antibacterial activity against mastitis-causing bacteria. Vet World. 2020;13:1187-1192.

33. Beta $\mathrm{T}$, Hwang $\mathrm{T}$. Influence of heat and moisture treatment on carotenoids, phenolic content, and antioxidant capacity of orange maize flour. Food Chem. 2018;246:58-64.

34. Hancock CO, Lambert PA, Dusseau JY, Duroselle P, Freney J, McDonnell G, Walsh SE, Denyer SP. Sterilization Processes. In: Fraise AP, Maillard JY, Sattar S, eds. Russell, Hugo \& Ayliffe's Principles and Practice of
Disinfection, Preservation and Sterilization ( $5^{\text {th }}$ ed). Oxford; WileyBlackwell; 2013:277-370.

35. Abdeltawab H, Svirskis D, Sharma M. Formulation strategies to modulate drug release from poloxamer based in situ gelling systems. Expert Opin Drug Deliv. 2020;17:495-509.

36. Matejczyk M, Świsłocka R, Golonko A, Lewandowski W, Hawrylik E. Cytotoxic, genotoxic and antimicrobial activity of caffeic and rosmarinic acids and their lithium, sodium and potassium salts as potential anticancer compounds. Adv Med Sci. 2018;63:14-21.

37. Muñoz-Muñoz JL, Garcia-Molina F, Ros E, Tudela J, García-Canovas F, Rodriguez-Lopez JN. Prooxidant and antioxidant activities of rosmarinic acid. J Food Biochem. 2013;37:396-408.

38. Alves TM, Silva AF, Brandão M, Grandi TS, Smânia E, Smânia Júnior $A$, Zani CL. Biological screening of Brazilian medicinal plants. Mem Inst Oswaldo Cruz. 2000;95:367-373.

39. Malahubban M, Alimon AR, Sazili AQ, Fakurazi S, Zakry FA. Phytochemical analysis of Andrographis paniculata and Orthosiphon stamineus leaf extracts for their antibacterial and antioxidant potential. Trop Biomed. 2013;30:467-480.

40. Exner M, Bhattacharya S, Christiansen B, Gebel J, Goroncy-Bermes P, Hartemann P, Heeg P, Ilschner C, Kramer A, Larson E, Merkens W, Mielke M, Oltmanns P, Ross B, Rotter M, Schmithausen RM, Sonntag HG, Trautmann M. Antibiotic resistance: what is so special about multidrug-resistant gram-negative bacteria? GMS Hyg Infect Control. 2017;12:Doc05.

41. Aisha AF, Majid AM, Ismail Z. Preparation and characterization of nano liposomes of Orthosiphon stamineus ethanolic extract in soybean phospholipids. BMC Biotechnol. 2014;14:23.

42. Thakor S, Vhora I, Desai J, Thakkar S, Thakkar H. Physiologically activated phase transition systems for improved ocular retention of ketorolac tromethamine. J Pharm Bioallied Sci. 2012;4(Suppl 1):S6-S7.

43. Savjani KT, Gajjar AK, Savjani JK. Drug solubility: importance and enhancement techniques. ISRN Pharm. 2012;2012:195727.

44. Shrestha K, Walsh K, Midmore D. Microbially enhanced compost extract: does it increase solubilisation of minerals and mineralisation of organic matter and thus improve plant nutrition? J Bioremediat Biodegrad. 2012;3:1-9. 